\title{
THE SPATIAL MECHANISM AND DRIVE MECHANISM STUDY OF CHINESE URBAN EFFICIENCY - BASED ON THE SPATIAL PANEL DATA MODEL
}

\author{
Yuan Xiaoling* and Chen Ali \\ School of Economics and Finance of Xi'an Jiaotong University, Xi'an, Shaanxi, China
}

In this article, the urban efficiency factors of 285 Chinese prefecture-level cities in the period from 2003 to 2012 are analyzed by using the spatial econometric model. The result shows that the development of urban efficiency between the cities positively correlates with space. And we conclude that the Industrial Structure, Openness and the Infrastructure can promote the development of such urban efficiency. The Urban Agglomeration Scale, Government Control, Fixed Asset Investment and other factors can inhibit the development of urban efficiency to a certain degree. Therefore, we come to a conclusion that, in the new urbanization construction process, the cities need to achieve cross-regional coordination from the perspective of urban agglomerations and metropolitan development. The efficiency of the city together with the scientific and rational flow of the factors should also be improved.

Keywords: urban efficiency, SBM model, spatial econometric model, factors flow

\section{JEL Classification: R12}

\section{INTRODUCTION}

The city is the political, economic and cultural center of the region (LI Xun, XU Xianxiang \& CHEN Haohui, 2005). The city should pursue high efficiency goals. And there are many ways to study urban efficiency. But A. Charnes, W. Cooper and S. Li (1989) indicated clearly that the Data Envelopment Analysis (DEA) is particularly suitable for the evaluation of the urban efficiency of this complex system. In recent years, many scholars studying urban efficiency use the DEA

\footnotetext{
* Correspondence to: Y. Xiaoling, School of Economics and Finance of Xi'an Jiaotong University, Yanta West Road 74, Xi'an, Shaanxi, China; e-mail: 992197013@qq.com
}

method to carry out extensive empirical research (Li Bozhi, 1987; Getis \& Ord, 1992; Anselin, 1995; Anselin, 1996; Ma Limei \& Zhang Xiao, 2004; Wang Hongling, Li Daokui \& Feng Junxin, 2006; Li Pei, 2007; Yuan Xiaoling, Zhang Baoshan \& Zhang Xiaoni, 2008; Jiang Wei, 2009; Dai Yongan, 2010; Zhang Haoran \& Yi Baozhong, 2012; Zeng Zhaofa \& Zuo Jie, 2013; Sun Yaohua \& Zhong Weizhou, 2014; Xu Min \& Jiang Yong, 2014). Xu Jian-wei, Xu Xin-yu, Chen Xing-peng et al (2013), took 12 prefecture-level cities in Gansu Province, China, as the samples to study the urban efficiency of Gansu Province in the period 2005-2009 by applying the method of the DEA Cross Evaluation Model in 2013. They concluded that the urban efficiency of Gansu Province is low in general, and the 
differences between the cities are significant. Sun Wei and Dong Guanpeng (2010) used the DEA model and the Malmquist productivity index to study 24 typical resource-based cities' efficiency and changes in China in 2000 and 2008. They found that only a few cities had reached the optimum overall urban efficiency and scale efficiency is the major factor in determining the overall urban efficiency. Tao Xiao-ma, Tan Jing and Chen $\mathrm{Xu}$ (2013) used as the input factor urban energy, land and water, which are the elements of natural resources, beside labor and capital, by using the data for the 16 cities in the Yangtze River Delta, China, in the period 1999-2010. They studied urban static efficiency, the efficiency of using the elements and the total factor productivity. They thus found out that scale efficiency contributes a lot to the promotion of urban efficiency, but the contributions gradually stagnated after 2003.

However, by reviewing the literature, we found out that in the research studies for the factors of urban efficiency most scholars considered the internal factors of urban efficiency in isolation (Li Bozhi, 1987; Anselin, 1996; Ma Limei \& Zhang Xiao, 2004; Li Pei, 2007; Yuan Xiaoling, Zhang Baoshan \& Zhang Xiaoni, 2008; Jiang Wei, 2009; Dai Yongan, 2010; Sun Wei \& Dong Guanpeng, 2010; Tao Xiao-ma, Tan Jing \& Chen $\mathrm{Xu}, 2013 ; \mathrm{Xu}$ Jian-wei, $X u$ Xin-yu, Chen Xing-peng et al, 2013; Zeng Zhaofa \& Zuo Jie, 2013; Sun Yaohua \& Zhong Weizhou, 2014), such as the local economy, society and geography factors, but neglected the interaction between the cities. The elements flow, product exchange, technology diffusion and other factors among the cities will all influence urban efficiency. So, neglecting the spatial effect will lead to the deviation of analytic results, even to a wrong conclusion. The past studies have paid insufficient attention to the spatial effect, which restricts research in the efficiency of the city. At the same time, the past studies involving space factors have shown that the sample spatial interaction plays a more significant role in the economic activity, and that the spatial econometric model is more conforming to the actual economic activity than the traditional panel model that can explain the economic phenomena better.

In this article, research is done in the following areas: Firstly, the SBM-undesirable model is used in order to measure urban efficiency and analyze the space characteristics of evolution. Secondly, the urban panel data introducing the spatial econometric model are used in order to explore the adjacent urban efficiency levels' spatial spillover effects and explain the factors influencing Chinese urban efficiency. Thirdly, some ways to improve urban efficiency have been proposed, expecting to support a rational and scientific reference for the development of Chinese urbanization construction.

\section{THE RESEARCH METHODS}

\section{The global spatial correlation analysis approach}

As the earliest calculation method applied to global clustering inspection, Moran's I index (Moran, 1948), has widely been used to test global spatial correlation. The index reflects the degree of the similarity of the areas cell property values that are space adjacent. The index can test if adjacent regions in the entire study areas have positive space correlation, negative space correlation or are independent of each other. The computational formula is shown below:

$$
\begin{aligned}
\text { Moran' } I= & \frac{n \sum_{i=1}^{n} \sum_{j=1}^{n} w_{i j}\left(x_{i}-\bar{x}\right)\left(x_{j}-\bar{x}\right)}{\sum_{i=1}^{n} \sum_{j=1}^{n} w_{i j} \sum_{i=1}^{n}\left(x_{i}-\bar{x}\right)^{2}} \\
= & \frac{\sum_{i=1}^{n} \sum_{j=1}^{n} w_{i j}\left(x_{i}-\bar{x}\right)\left(x_{j}-\bar{x}\right)}{S^{2} \sum_{i=1}^{n} \sum_{j=1}^{n} w_{i j}} .
\end{aligned}
$$

In the formula (1), the variable $n$ represents all the numbers of the study areas, the variable $x_{i}$ represents the observation of the region $i$, the variable $x_{i}$ represents the observation of the region $j$. The variable $\bar{x}=\frac{1}{n} \sum_{i=1}^{n} x_{i}$ represents the average of the observation, $S^{2}=\frac{1}{n} \sum_{i=1}^{n}\left(x_{i}-\bar{x}\right)^{2}$ represents the variance of the observed value. The variable $w_{i j}$ represents the spatial weight matrix. 
In this paper, the "Queen Space Weight Method" is used in order to set the spatial weight matrix, and the set principle is shown below. The relative positions of the region $i$ and the region $j$ in geography as a judge, if the two regions are geographically adjacent, then we write $w_{i j}=1$; if not, we write $w_{i j}=0$, and if $i=j$, we write that $w_{i j}=0$. The "Queen Space Weight Method" defines "adjacency" in the meaning that there is a common vertex or boundary between regions.

The values of Moran's I index range between -1 and 1 , if Moran's $I>0$, it means that the region $i$ and the region $j$ are positively related, and if the values of Moran's $I$ are close to 1 , it indicates that there are similar observations assembling together, namely that the high-value region is adjacent to the high-value region and the low-value region is adjacent to the low-value region. If Moran's $I<0$, it means that the region $i$ and the region $j$ are negatively related, and if the values of Moran's I are close to -1, it indicates that there are dissimilar observations assembling together, namely that the high-value region is adjacent to the low-value region and the low-value region is adjacent to the highvalue region. If the value of Moran's I comes close to 0 , it indicates that the observations of the samples are distributed randomly, namely that there is no correlation between the observations of the samples.

\section{The local spatial correlation analysis approach}

L. Anselin (1995) introduced local Moran's I index, also called LISA. The Local Moran's I index is used to inspect whether the local region exists similarly or dissimilarly to the observations of the samples gathered together. And the formula is shown below:

$I_{i}=\frac{\left(x_{i}-\bar{x}\right)}{S^{2}} \sum_{j \neq i} w_{i j}\left(x_{j}-\bar{x}\right)$.

In the formula (2), $x_{i}$ represents the observation of the region $i, x_{j}$ represents the observation of the region $j$.

$\bar{x}=\frac{1}{n} \sum_{i=1}^{n} x_{i}$ represents the average of the observations, $S^{2}=\frac{1}{n} \sum_{i=1}^{n}\left(x_{i}-\bar{x}\right)^{2}$ represents the variance between the observed values. The variable $w_{i j}$ represents the spatial weight matrix, so we can see that the settings of $x_{i}, x_{j^{\prime}} \bar{x}, S^{2}$ and $w_{i j}$ are the same with the global Moran's $I^{\prime}$ settings. If the value of the $I_{i}$ index is positive, then it indicates that the high-value region is surrounded by high-value regions (high-to-high), or that the low-value region is surrounded by the low-value regions (low-tolow). If the value of the $I_{i}$ index is negative, then it indicates that the high-value region is surrounded by low-value regions (high-to-low), or that the low-value region is surrounded by high-value regions (low-tohigh).

A. Getis and J. K. Ord (1992) came up with the Geary index in order to inspect local clustering; the Geary index is used to inspect if the local regions exist with a statistically significant high or low value, it is also called the $G_{i}$ index. The formula is shown below:

$G_{i}=\sum_{j \neq i} w_{i j}{ }^{x_{j}} / \sum_{j \neq i} x_{j}$.

In the formula (3), $x_{i}$ represents the observation of the region $i, x_{j}$ represents the observation of the region $j$. $w_{i j}$ represents the spatial weight matrix, so the settings of $x_{i}, x_{j}$ and $w_{i j}$ are also the same as the global Moran's I settings. In the formula, if the value of $G_{i}$ is high, then it indicates that the samples with high values gather together. If the value of $G_{i}$ is low, then it indicates that the samples with low values gather together. So, by comparing the value of $G_{i^{\prime}}$ we can inspect if local regions exist with the spatial high-value clustering effect or the spatial low-value clustering effect.

\section{The Spatial Panel Model}

As the space of the human social activity increases, the spatial relationship between the region and an individual becomes closer. So, studying the spatial relationship between the regions is extremely important in economic analysis. Introducing the spatial weights matrix in the traditional econometric models, such as the Spatial Lag Panel Data Model and the Spatial Error Model, such a spatial relationship can effectively be portrayed. Thus, it is better to apply the Spatial Lag Panel Data Model and the Spatial Error Model in order to study the Space Agglomeration Mechanism and the Causes. 


\section{Spatial Lag Panel Data Model}

The Spatial Lag Panel Data Model is a classic space econometric model. It is extension model of the linear regression model; it is embedded in the lagged dependent variable in the general line of the regression equation. Namely, in the Spatial Lag Panel Data Model, the space variable of the explained variable is directly introduced into the panel model. The model is shown below:

$Y_{i t}=\rho \sum w_{i t} Y_{i t}+\beta X_{i t}+\mu_{i t}+\lambda_{i t}+\varepsilon_{i t}{ }^{\prime}$

$\varepsilon_{i t} \sim N\left(0, \sigma_{i t}^{2}\right)$.

In the formula (4), $\Sigma w_{i j} Y_{i j}$ represents the spatial variable, $w_{i j}$ represents the spatial weight matrix, so the setting of $w_{i j}$ is the same as the global Moran's I setting; $X$ is the matrix composed of independent variables. In the panel data analysis, the time effect and the individual effect cannot be neglected; $\mu_{i j}$ is the random perturbation terms of the time effect, the variable $\lambda_{i}$ is the random perturbation terms of the individual effect. $\varepsilon_{i j}$ is the random error term obeying the normal distribution. $\rho$ is the spatial auto-regressive coefficient, reflecting the degree of the spatial spillover effects and measuring the direction of the influence and the degree of the observations of the adjacent region in the local area.

\section{Spatial Error Model}

Because of the complexity of the regional spatial effect, the error term, which is very important in spatial relations when analyzing spatial econometrics, may be neglected; so, the panel error panel data model can be used in order to analyze the mutual relations between the regions in this paper; the formula is as follows:

$Y_{i t}=\beta X_{i t}+\mu_{i t}+\lambda_{i t}+\varphi_{i t}$,

$\varphi_{i t}=v \sum w_{i t} \varphi_{i t}+\varepsilon_{i t}, \quad \varepsilon_{i t} \sim N\left(0, \sigma_{i t}^{2}\right)$.

In the above equations, $\varphi_{i j}$ represents the residuals of the spatial auto-correlation, it is composed of $\varphi_{i j}$ and $\varepsilon_{i j^{\prime}}$ where $\varphi_{i j}$ represents the residuals of the adjacent area and $\varepsilon_{i j}$ the random error term, obeying the normal distribution. $v$ is the space error coefficient, reflecting the influence degree of adjacent areas' observations perturbation terms to the local areas.

\section{MODEL SETTING AND DATA PROCESSING}

\section{Variable selection}

First, variable urban efficiency (UE) was introduced. In this paper, the SBM model containing the undesired output is used in order to measure the urban efficiency of about 285 Chinese prefecture-level cities in the period from 2003 to 2012. So, the input indicators, the expected output indicators and the undesired output indicators are used as the evaluation standard. The specific index is accounted for in Table 1.

Building on the index system is the basic work to be done in the evaluation of the economic system,

Table 1 Chinese urban efficiency measurement indicators

\begin{tabular}{|c|c|c|c|}
\hline Target layer & Guidelines & layer & Index layer \\
\hline \multirow{8}{*}{$\begin{array}{l}\text { Urban } \\
\text { efficiency }\end{array}$} & \multirow{3}{*}{$\begin{array}{l}\text { Input } \\
\text { indicators }\end{array}$} & $\begin{array}{l}\text { Land } \\
\text { investment }\end{array}$ & Built-up area \\
\hline & & Labor input & Capital stock of assets \\
\hline & & $\begin{array}{l}\text { Capital } \\
\text { investment }\end{array}$ & $\begin{array}{l}\text { Employment in the } \\
\text { secondary and the } \\
\text { tetriary sectors }\end{array}$ \\
\hline & \multirow{3}{*}{$\begin{array}{l}\text { Expected } \\
\text { output } \\
\text { indicators }\end{array}$} & $\begin{array}{l}\text { Economic } \\
\text { benefits }\end{array}$ & $\begin{array}{l}\text { The secondary and the } \\
\text { tertiary industries output }\end{array}$ \\
\hline & & $\begin{array}{l}\text { Social } \\
\text { benefits }\end{array}$ & The total social retail \\
\hline & & $\begin{array}{l}\text { Ecological } \\
\text { benefits }\end{array}$ & City garden area \\
\hline & \multirow{2}{*}{$\begin{array}{l}\text { Undesired } \\
\text { output } \\
\text { indicators }\end{array}$} & \multirow{2}{*}{$\begin{array}{l}\text { Pollution } \\
\text { emissions }\end{array}$} & $\begin{array}{l}\text { The discharge of } \\
\text { industrial waste water }\end{array}$ \\
\hline & & & $\begin{array}{l}\text { The discharge of } \\
\text { industrial waste gas }\end{array}$ \\
\hline
\end{tabular}

Source: Authors 
because the indicators selection has a great influence on evaluation results. In this paper, according to the existing urban efficiency theory and empirical research, and based on the data availability, we think the main factors affecting the efficiency of the city include the following (Charnes, Cooper \& Li, 1989):

- Industrial Structure (IS). The industrial structure reflects the economic structure and the development model of a region. According to the Petty Clark Theorem and the reality of Chinese urban development. In this paper, the proportion of the added value of the secondary and the tertiary industries in the total output of the city are used to measure the impact of the industrial structure on the efficiency of the city;

- Urban Agglomeration Scale (Sc). In total, urban development adheres to the following rules: with the enhancement of Urban Agglomeration, the population will continue to shift its focus from rural to urban areas, which will lead to the continuous expansion of the urban built-up area. However, the rapid and continuous expansion of the urban built-up area will result in the decreased efficiency of land use, which can affect the output efficiency of the city. So, in this paper, the built-up area representing the proportion of the urban areas as the metrics of the urban degree of aggregation is used;

- Fixed Asset Investment (Iv). The level of investment in different regions varies greatly; investment directions are also different in different regions, so the impact of the level of fixed assets investment on the urban efficiency also differs in different cities. Considering the data availability and the effectiveness of measures, the ratio of fixed asset investment and the city's output are chosen to represent the urban fixed asset investment level;

- Government Control (Gov). The Chinese local government's spending levels will reflect the efficiency of the government to a certain extent. It also reflects the influences of the institutional factor on urban efficiency. The spending levels in different local governments vary greatly in China, so the local-government administrative coefficients also differ, which means that a different administrate efficiency can influence urban efficiency. So, in this paper, the ratio of the government's expenditure and the city's output are chosen as a variable to measure the level of the government's spending;

- Openness (FDI). It has been more than 30 years since the reform and the opening up in China, and the openness in different cities varies a lot. Relatively speaking, due to the geographical factors, there is a high degree of openness in the coastal cities, whereas the inland cities are characterized by a low degree of such openness. Foreign investment and the modern management level are also different, for which reason this will inevitably have an impact on the output efficiency variance of the cities to a certain degree. Therefore, considering the data availability, the ratio of the urban actual use of foreign investments and the city's output are chosen in this paper in order to measure the degree of the influences of urban openness on urban efficiency;

- Infrastructure (Inf). The rapid construction and improvements of the infrastructure can accelerate the dissemination of information and lower transaction costs. It contributes to the quality of economic development, thus improving urban efficiency. For that reason, in this paper, the per capita area of the paved roads in every city is chosen so as to measure the degree of the impact of the infrastructure on urban efficiency.

\section{Data sources and description}

In this paper, 285 Chinese prefecture-level cities observed in the period from 2003 to 2012 are chosen as the study samples. (By 2013, there have been 289 prefecture-level cities, whereas there are 4 cities for which data cannot be collected; so, in this paper, when the data availability is concerned, the following cities are excluded, namely: Lhasa City, Sansha City, Tongren City and Bijie City; the regions of Hong Kong, Macao and Taiwan are also excluded.) The basic data have been obtained from the China City Statistical Yearbook (from 2004 to 2013), the China Urban Construction Statistical Yearbook (from 2004 to 2013) and the China Statistical Yearbook (from 2004 to 2013). 
The MaxDEA Pro 5.2 software is used in order to measure urban efficiency, and the GeoDa and R are then used to estimate the Spatial Penal Data.

\section{Model set}

According to the definition of the two spatial models above, the urban efficiency driving mechanism panel data model is set, which, considering the spatial effects, is as follows:

- The Spatial Lag Model:

$$
\begin{aligned}
U E_{i t} & =\beta_{0}+\beta_{1} I S_{i t}+\beta_{2} C S_{i t}+\beta_{3} I v s_{i t}+\beta_{4} G_{o v}+ \\
& +\beta_{5} F D I_{i t}+\beta_{6} I n f_{i t}+\rho \sum w_{i t} U E_{i t}+\varepsilon_{i t} \\
\varepsilon_{i t} & \sim N\left(0, \sigma_{i t}^{2}\right) .
\end{aligned}
$$

In the formula (8), $U E_{i t}$ is the dependent variable representing urban efficiency; $\beta_{0}, \beta_{1}, \beta_{2}, \beta_{3}, \beta_{4}, \beta_{5}$ and $\beta_{6}$ represent the coefficients of the arguments; $\rho$ is the spatial auto-regressive coefficient reflecting the degree of the spatial spillover effects, and it measures the direction of the influence and the degree of the observations of the adjacent region to the local area. $\sum w_{i j} U E_{i j}$ represents the spatial variable, $w_{i j}$ represents the spatial weight matrix, $\varepsilon_{i j}$ is the random error term and obeys the normal distribution.

- The Spatial Error Model:

$$
\begin{aligned}
& U E_{i t}= \beta_{0}+\beta_{1} I S_{i t}+\beta_{2} C S_{i t}+\beta_{3} I v s_{i t}+\beta_{4} G v_{i t}+ \\
&+\beta_{5} F D I_{i t}+\beta_{6} I n f_{i t}+\varepsilon_{i t} \\
& \varepsilon_{i t}=\lambda \sum w_{i t} \varepsilon_{i t}+\varphi_{i t}, \quad \varphi_{i t} \sim N\left(0, \sigma_{i t}^{2}\right) .
\end{aligned}
$$

In the formula (9), $U E_{i t}$ is the dependent variable representing urban efficiency; $\beta_{0}, \beta_{1}, \beta_{2}, \beta_{3}, \beta_{4}, \beta_{5}$ and $\beta_{6}$ represent the coefficients of the arguments. $\varepsilon_{i t}$ is the random error term, representing the residuals of the spatial auto-correlation and is composed of $\varphi_{i t}$ and $\varepsilon_{i t}, \varphi_{i t}$ representing the residuals of the adjacent area, $\varepsilon_{i t}$ being a random error term obeying the normal distribution. The variable $v$ is the space error coefficient reflecting the degree of the influence of the adjacent areas' observations perturbation terms on the local areas.

\section{EMPIRICAL ANALYSIS}

\section{The empirical analysis of the Spatial Agglomeration of urban efficiency}

\section{Global spatial correlation}

Before carrying out the space panel model regression analysis, the spatial correlation of the data should be tested. If such spatial correlation exists, then the Spatial Econometric Model is used, avoiding the biased estimate generated by the spatial factors. In this paper, in order to verify whether Chinese urban efficiency is characterized by spatial correlation, the formula (1) is used to calculate Chinese urban efficiency global Moran's I value; if the value of Moran's I $>0$, it means that the region $\mathrm{i}$ and the region $\mathrm{j}$ are positively related, and the calculation result is presented in Table 2 .

In Table 2, E(I) is calculated by $-1 /(\mathrm{n}-1)$, which represents the expected value of Moran's I. Sd(I) represents the variance of Moran's I. z represents the z-test value of Moran's $I$. The $P$-value is given along with probability, and it is obtained through the Monte Carlo experiment with 999-time simulation. Table 2 reflects that global Moran's I values are all positive, and the $z$-test values are significant, all exceeding the $1 \%$ significance level test. So, it can be concluded that, when urban efficiency

Table 2 Chinese urban efficiency global Moran's I index statistical indicators value

\begin{tabular}{c|ccccc}
\hline Year & Moran's $I$ & $E(I)$ & $S d(I)$ & $z$ & $P$-value \\
\hline 2003 & 0.3388 & -0.0035 & 0.0416 & 8.2566 & 0.001 \\
2004 & 0.3049 & -0.0035 & 0.0412 & 7.4710 & 0.001 \\
2005 & 0.2416 & -0.0035 & 0.0405 & 6.0508 & 0.001 \\
2006 & 0.2155 & -0.0035 & 0.0408 & 4.9111 & 0.002 \\
2007 & 0.1938 & -0.0035 & 0.0422 & 4.7148 & 0.001 \\
2008 & 0.1970 & -0.0035 & 0.0413 & 4.8601 & 0.001 \\
2009 & 0.2171 & -0.0035 & 0.0405 & 5.4350 & 0.001 \\
2010 & 0.2143 & -0.0035 & 0.0409 & 5.3281 & 0.001 \\
2011 & 0.2335 & -0.0035 & 0.0426 & 5.5762 & 0.001 \\
2012 & 0.2108 & -0.0035 & 0.0414 & 5.1822 & 0.001 \\
\hline
\end{tabular}

Source: Authors 
is concerned, there is an obvious positive spatial correlation among the Chinese prefecture-level cities.

\section{Local spatial correlation}

The local spatial correlation index, namely LISA, is used so as to measure the local spatial characteristics of Chinese urban efficiency. According to the formula (2), the data are calculated and the Chinese urban efficiency local gathering map is drawn. The agglomeration areas all exceed the $5 \%$ significance test.

Figure 1 enables us to see that the first box represents "not significant"; the second box represents "high-tohigh" cities agglomeration; the third box represents "low-to-low" cities agglomeration; the forth box represents "low-to-high" cities agglomeration; the fifth box represents "high-to-low" cities agglomeration; the last box represents the non-prefecture level cities. Figure 1 shows that the "low-to-low" cities agglomeration type is centralized mainly in Hebei Province, Shaanxi Province and Gansu Province, and in the border region of Jiangsu Province and Anhui Province, there are some low efficiency cities. The "high-to-high" cities agglomeration type is mainly centralized in 2 regions: in Heilongjiang Province in the northeast of China and the Pearl River Delta region in the south of China.

On the basis of testing the Chinese urban-efficiency spatial distribution by using the global and local Moran's I index, the cities spatial correlation Gi index

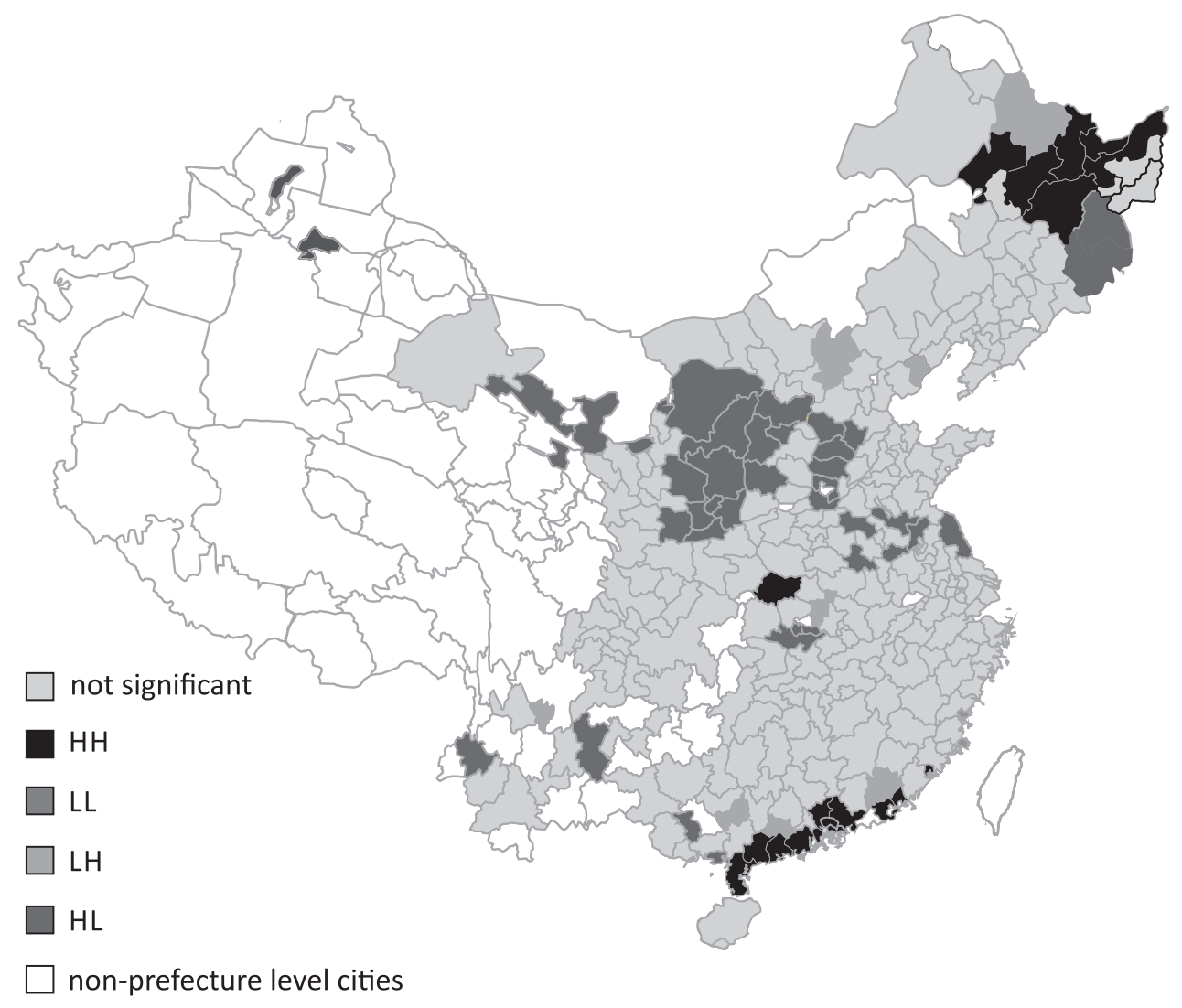

Figure 1 The efficiency of the Chinese prefecture-level and above-prefecture-level cities, LISA agglomeration figure in 2003 
is also applied together with the ArcGIS software, only to be followed by our applying the natural fracture method so as to divide the Gi index into three categories. The high $\mathrm{Gi}$ index value means that the cities with high urban efficiency gather there (the hotspot region); the low $\mathrm{Gi}$ index value means that the cities with low urban efficiency gather there (the cold-spot region); if the $\mathrm{Gi}$ index value is close to zero, it indicates that there is no obvious special agglomeration.

Figure 2 shows that the first box represents "not significant"; the second box represents the hotspot region; the third box represents the cold-spot region; and the last box represents the non-prefecture level cities. Figure 2 shows that Chinese urban efficiency cold-spot regions are similar to the LISA agglomeration results in space; they are mainly centralized in Hebei
Province, Shanxi Province, Shaanxi Province and Gansu Province. Chinese urban efficiency hot-spot regions are mainly centralized in the northeast of China and the Pearl River Delta region in the south of China, whereas some cities are located in Bohai Rim and Hubei Province.

The FIG Partial Agglomeration is estimated and drawn by using the Geo DA software. This paper has drawn the gathering local map for the period from 2003 to 2012; due to the limited space, however, the representative map. Ditto. is only listed.

\section{Spatial Econometric Analysis to Urban Efficiency Drive Mechanism}

Based on the above test results, estimations according to the formula (8) and the formula (9) are made by

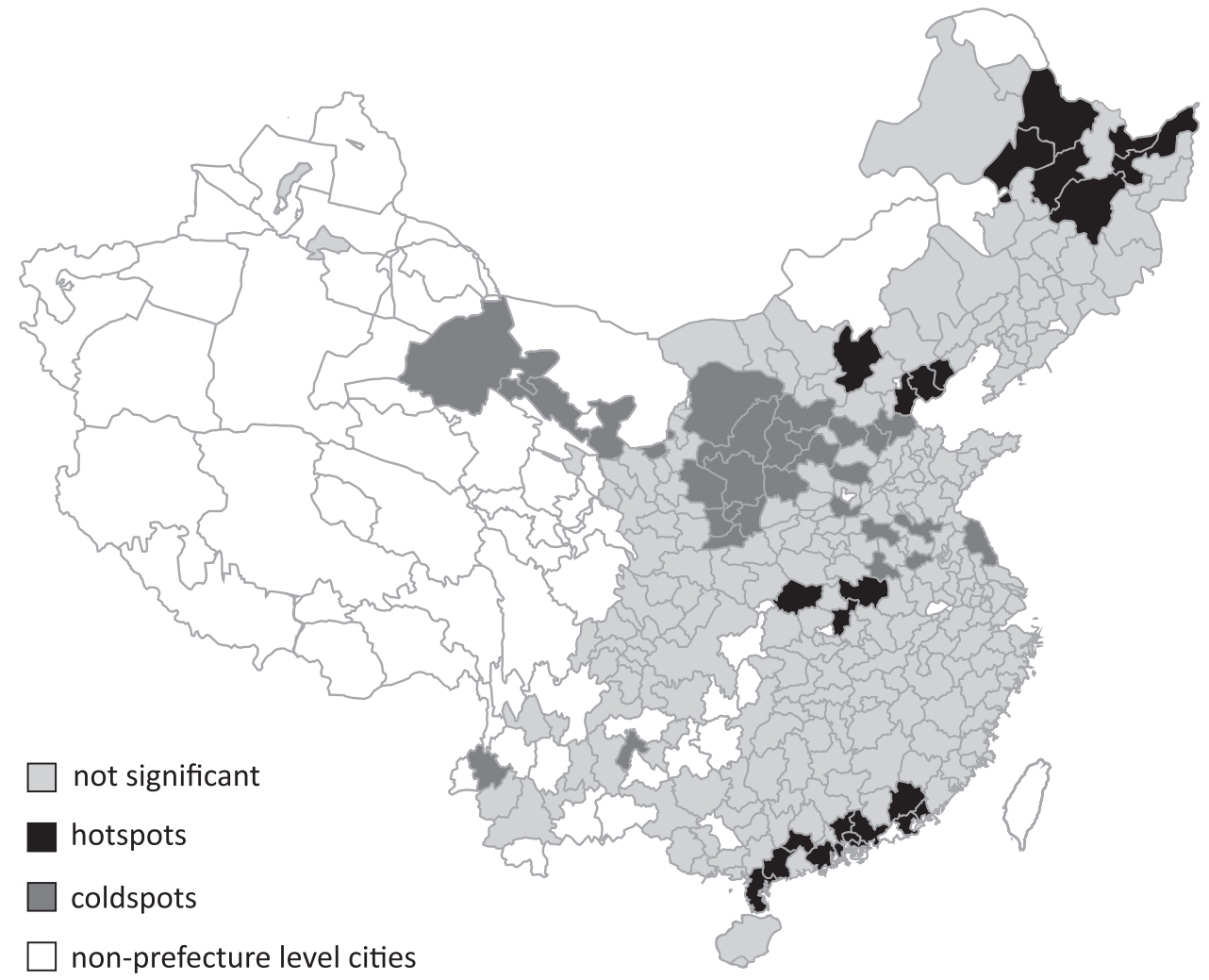

Figure 2 The efficiency hot- and cold spots figure of the Chinese prefecture-level cities in 2003 
using the software $\mathrm{R}$, and the result of the calculation is given in Table 3 , in which ${ }^{* * *}$,** and ${ }^{*}$ reflect that the statistics exceed the $1 \%, 5 \%$ and $10 \%$ significance level tests, respectively; the content in brackets represents the $t$ value of the statistics, the content in brackets of the spatial correlation diagnostic tests represent the level of the $p$ value.

According to the spatial data model options method (Anselin, 1996), the results of the measurement Table 3 can be analyzed. When analyzing the LM-lag and the LM-error, we can see that the value of the LM- lag and the LM-error both exceed the 1\% level of the significance test. When analyzing the Robust LM-lag and the Robust LM-error, we can see that the $t$ value of the Robust LM-lag is 0.128 , so the Robust LM-lag does not exceed the significance test. Therefore, according to the results of the calculation, the spatial error panel data model (SEM) is selected. When analyzing the Hausman test, we come to a conclusion that the fixed effects, removed from the Random effects should be selected. So, in conclusion, the Model 5 with the fixed effects is used in order to carry out the analysis in this paper.

Table 3 The comparison of the three kinds of the estimation results of the regression model

\begin{tabular}{|c|c|c|c|c|c|c|}
\hline & \multicolumn{2}{|c|}{ Basic panel data model } & \multicolumn{2}{|c|}{ Spatial lag panel data model } & \multicolumn{2}{|c|}{ Spatial error panel data model } \\
\hline & $\begin{array}{c}\text { Model } 1 \\
\text { Fixed effects } \\
\text { LSDV estimation }\end{array}$ & $\begin{array}{c}\text { Model } 2 \\
\text { Random effects } \\
\text { GLS estimation }\end{array}$ & $\begin{array}{c}\text { Model } 3 \\
\text { Fixed effects } \\
\text { ML value }\end{array}$ & $\begin{array}{c}\text { Model } 4 \\
\text { Random effects } \\
\text { ML value }\end{array}$ & $\begin{array}{l}\text { Model } 5 \\
\text { Fixed effects } \\
\text { ML value }\end{array}$ & $\begin{array}{c}\text { Model } 6 \\
\text { Random effects } \\
\text { ML value }\end{array}$ \\
\hline$C$ & & $\begin{array}{c}0.2815^{* * *} \\
(14.450)\end{array}$ & & $\begin{array}{c}0.2362^{* * *} \\
(11.733)\end{array}$ & & $\begin{array}{c}0.2973^{* * *} \\
(13.717)\end{array}$ \\
\hline Industrial Structure & $\begin{array}{c}0.0024^{* * *} \\
(5.880)\end{array}$ & $\begin{array}{c}0.0029 * * * \\
(7.560)\end{array}$ & $\begin{array}{c}0.0023 * * * \\
(6.036)\end{array}$ & $\begin{array}{c}0.0026 * * * \\
(7.011)\end{array}$ & $\begin{array}{c}0.0023^{* * *} \\
(6.054)\end{array}$ & $\begin{array}{c}0.0027^{* * *} \\
(7.035)\end{array}$ \\
\hline City size & $\begin{array}{l}-0.0007^{*} \\
(-1.850)\end{array}$ & $\begin{array}{l}-0.0003 \\
(-0.810)\end{array}$ & $\begin{array}{l}-0.0007^{*} \\
(-1.826)\end{array}$ & $\begin{array}{l}-0.0004 \\
(-0.946)\end{array}$ & $\begin{array}{l}-0.0006^{*} \\
(-1.653)\end{array}$ & $\begin{array}{l}-0.0003 \\
(-0.771)\end{array}$ \\
\hline Fixed asset investment & $\begin{array}{c}-0.0532 * * * \\
(-5.150)\end{array}$ & $\begin{array}{c}-0.0690 * * * \\
(-6.630)\end{array}$ & $\begin{array}{c}-0.0520 * * * \\
(-5.347)\end{array}$ & $\begin{array}{c}-0.0623^{* * *} \\
(-6.167)\end{array}$ & $\begin{array}{c}-0.0562 * * * \\
(-5.640)\end{array}$ & $\begin{array}{c}-0.0679^{* * *} \\
(-6.531)\end{array}$ \\
\hline Government control & $\begin{array}{l}-0.0180 \\
(-0.4300\end{array}$ & $\begin{array}{l}-0.0758^{*} \\
(-1.820)\end{array}$ & $\begin{array}{l}-0.0141 \\
(-0.358)\end{array}$ & $\begin{array}{l}-0.0525^{*} \\
(-1.294)\end{array}$ & $\begin{array}{l}-0.0183 \\
(-0.455)\end{array}$ & $\begin{array}{l}-0.0568 * \\
(-1.372)\end{array}$ \\
\hline Openness & $\begin{array}{c}0.2613^{* * *} \\
(2.810)\end{array}$ & $\begin{array}{l}0.0826 * \\
(0.900)\end{array}$ & $\begin{array}{c}0.2635^{* *} \\
(3.014)\end{array}$ & $\begin{array}{l}0.1482 * \\
(1.653)\end{array}$ & $\begin{array}{c}0.2020 * * \\
(3.329)\end{array}$ & $\begin{array}{c}0.1985^{*} \\
(2.117)\end{array}$ \\
\hline Infrastructure & $\begin{array}{l}0.0004 \\
(0.720)\end{array}$ & $\begin{array}{c}0.0016 * * * \\
(2.960)\end{array}$ & $\begin{array}{l}0.0002 \\
(0.721)\end{array}$ & $\begin{array}{c}0.0009^{*} \\
(1.812)\end{array}$ & $\begin{array}{l}0.0001 \\
(0.169)\end{array}$ & $\begin{array}{c}0.0006^{*} \\
(1.135)\end{array}$ \\
\hline$\rho$ & & & $\begin{array}{c}0.1360 * * * \\
(6.038)\end{array}$ & $\begin{array}{c}0.1558^{* * *} \\
(6.920)\end{array}$ & & \\
\hline$\lambda$ & & & & & $\begin{array}{c}0.1477^{* * *} \\
(7.062)\end{array}$ & $\begin{array}{c}0.1681 * * * \\
(7.309)\end{array}$ \\
\hline Adjusted $\mathrm{R}^{2}$ & 0.508 & 0.395 & 0.489 & 0.366 & 0.386 & 0.327 \\
\hline Log likelihood & 3000.488 & 2819.329 & 3027.950 & 2342.918 & 3030.334 & 2045.519 \\
\hline & & Spatial correl & coll und & & & \\
\hline Hausman test & LM-lag & Rob & ust LM-lag & LM-error & & bust LM-error \\
\hline $\begin{array}{c}88.825^{* * *} \\
(0.000)\end{array}$ & $\begin{array}{c}133.756 * * * \\
(0.000)\end{array}$ & & $\begin{array}{l}2.317 \\
0.128)\end{array}$ & $\begin{array}{c}148.924^{* * *} \\
(0.000)\end{array}$ & & $\begin{array}{c}17.485^{* * *} \\
(0.000)\end{array}$ \\
\hline
\end{tabular}

Source: Authors 
The above regression results show that the spatial lag regression coefficient $\varrho$ and the spatial error regression coefficient $\lambda$ are significantly positive at the $1 \%$ level. It indicates that interurban externalities have significant impact on urban efficiency. In this paper, there are 3 reasons thought to be capable of explaining this phenomenon. First, with the rapid development of urbanization in China, the City Group, as the main form of urban development, achieved remarkable results. The changes reflected in the form of the rapid formation of the urban agglomeration, the economic strength of the central city and the core radiation steadily increasing enhance the overall increase in urban efficiency. Second, cooperation between the cities is enhancing and the urban industrial structure is diversified. At early stages, the developmental goals among the cities are very similar, especially in manufacturing, which results in the waste of the use of regional resources. In recent years, with the uniform adjustment of the urban development strategy, the overall efficiency between the cities is improved. Third, between the neighboring cities, the rapid spread of innovation knowledge and expertise is beneficial to the rational allocation of the resources, which promotes inter-regional innovative gathering.

According to the calculation result of the model, we can conclude that the industrial structure, urban openness, the infrastructure and the other factors have a positive effect on urban efficiency. The size of a city, fixed asset investment and the government's control have a negative impact on urban efficiency. The level of the infrastructure and the impact of the government's control do not pass the significance level test.

We can see that the regression coefficient of the industrial structure at the $1 \%$ significance level is significantly positive, and has a positive impact on urban efficiency. When the total value of the second and the tertiary industries accounted for a proportion of the total GDP of the city increasing $1 \%$, urban efficiency grows $0.23 \%$. Although the Chinese urbanization process is accelerating, China is still in mid-industrialization. The adjustment of the industrial structure is a potential for economic growth. Only by transforming its economic growth model and by developing a modern service industry can China improve its urban efficiency. According to the results of the conducted analysis, we can see that the city sale inhibits the efficiency of the city, and this article provides an explanation of this phenomenon. The first reason is that the cities in the development process attract a large number of rural labor into the cities, after which the population explosion causes urban congestion, the commuting costs increase, which leads to an increase in the time wasted in such commuting. The second reason is that a large number of the constructions of industrial parks make the urban area grow, but the extensive development model of the industrial parks leads to a decrease in economic efficiency, which leads to a decline in the city's comprehensive output efficiency. From the result generated by the model, we can see that Investment in Fixed Assets has a negative effect on urban efficiency, when urban fixed asset investment accounted for the proportion of the urban total output increases, then China's urban efficiency declines. Chinese fixed asset investment is mainly in the cement, steel, real estate and other industry, which is overcapacity. Repetitive manufacture leads to the low output efficiency of these industries, which in turn leads to low urban efficiency. Besides, we can see that FDI has a positive effect on urban efficiency, which is positively explained by the fact that foreign direct investment is mainly concentrated in the high-tech industry, which has a significant effect on urban efficiency. In order to attract more foreign direct investments, the cities promote the urban output by offering better supporting measures and preferential conditions, for which reason the method is beneficial for improving urban efficiency. The government's control has a negative effect on urban efficiency, indicating that stronger government's control leads to a worse degree of the market, which provokes a decline in urban efficiency. From the $\mathrm{Xu}$ Min and Jiang Yong study (2014), we can see that the degree of the market not only has an effect on local urbanization, but also has a spillover effect on the neighboring cities.

\section{CONCLUSION}

In the period of the rapid development of urbanization, research into urban efficiency plays an important part in improving the quality of such urbanization. In this 
paper, the SBM-undesirable model containing the undesirable output is constructed and an objective evaluation of the prefecture-level cities' urban efficiency is made. The factors influencing the efficiency of the city is then analyzed, using the spatial economic model. According to the results of the analysis, the following three conclusions can be drawn.

First, the evaluation structure of the SBM-undesirable model differs greatly from the traditional DEA evaluation structure, urban efficiency faces a great decline if the SBM-undesirable model is used, for which reasons this evaluation method is more representative. In the period 2003-2012, the Chinese prefecture-level cities' urban efficiency reflects a great difference: spatially, the eastern region shows to have high urban efficiency, whereas the western region shows to have low urban efficiency.

Second, the Chinese prefecture-level cities' urban efficiency has significant spatial correlation, the urbanization agglomeration phenomenon is more pronounced and as such brings the cities settlement, such as the Pearl River Delta region and the Wuhan Urban Agglomeration. So, the spatial correlation between cities should be considered when researching the Urbanization. In the process of building urban agglomerations, the Chinese government should exert a spatial spillover effect between the cities and promote the development of inter-city cooperation. Besides, the government should promote the rational cross-regional allocation of the resource elements in order to promote sustainable urban development.

Third, amongst the factors influencing urban efficiency, the industrial structure, the degree of openness and the degree of the infrastructure development have a positive effect on urban efficiency; however, the degree of the infrastructure development do not pass the statistically significant test. Instead, the city size, fixed asset investment and the government's control have a negative effect on urban efficiency. Thus, under the constraint of the limited resources, the government should arrange reasonable expenses and improve investment efficiency so as to promote sustainable urban development.
According to the above conclusions, the main contribution of the paper is reflected in that it provided a scientific theory support to the government when they determined the urban construction and development programs. The Chinese government should consider the spatial correlation between the cities rather than develop the city in isolation from other ones. In the process of building urban agglomerations, the Chinese government should promote the development of intercity cooperation. Besides, the government should promote the rational cross-regional allocation of the resource elements in order to promote sustainable urban development.

According to the existing urban efficiency theory, and based on the data availability, the paper only chose 6 variables as the factors to analyze urban efficiency; there may, however, be the other factors influencing the variety of urban efficiency; so, in the future, we will do further research in order to explore more potential factors. Because of the missing data, the time span of this paper is only from 2003 to 2012. The time span has a great influence on the measurement results; so, in a further study, the time span can be stretched.

\section{REFERENCES}

Anselin, L. (1995). Local indicators of spatial association LISA. Geographical Analysis, 27(2), 93-115. doi: 0.1111/j.15384632.1995.tb00338.x

Anselin, L. (1996). The Moran Scatter as an ESDA Tool Assess Local Instability in Spatial Association. London, UK: Taylor and Francis.

Charnes, A., Cooper, W. W., \& Li S. (1989). Using data envelopment analysis to evaluate efficiency in the economic performance of Chinese cities. Socio-Economic Planning Science, 23(6), 325-344. doi:10.1016/0038-0121(89)90001-3

Dai Yongan. (2010). Chinese urbanization efficiency and influencing factors - Analysis based on stochastic frontier production function. The Journal of Quantitative E Technical Economic, 12, 103-117+132

Getis, A., \& Ord, J. K. (1992).The analysis of spatial association by use of distance statistics. Geographical Analysis, 24(3), 189206. doi: 10.1111/j.1538-4632.1992.tb00261.x

Jiang Wei. (2009). Spatial econometric analysis of Chinese 
provincial urbanization influencing factors. Economic Geography, 4, 613-617.

Li Bozhi. (1987). Nanchang city efficiency exploration. Jiangxi Normal University, 4, 115-121.

Li Pei. (2007). China's urban economic growth efficiency and difference. The Journal of Quantitative \& Technical Economic, 7, 97-106.

LI Xun, XU Xianxiang, CHEN Haohui. (2004). Temporal and spatial changes of urban efficiency in the 1990s. Acta Geographica Sinica, 60(4), 615-625. doi: 10.11821/xb200504010

Ma Limei, \& Zhang Xiao. (2004). Spatial effects of China haze pollution and economic, the energy structure impact. China Industrial Economy, 4, 19-31.

Moran, P. A. P. (1948). The interpretation of statistical maps. Journal of the Royal Statistical Society, Series B. 10, 243-251.

Sun Wei, Dong Guan-peng. (2010). Chinese Resourcebased City Efficiency and Changes Based on DEA Model. Geographical Research, 29(12).

Sun Yaohua, \& Zhong Weizhou. (2014). Chinese provincial carbon intensity convergence study-based on spatial panel model. Economic Management Journal, 12, 31-40.

Tao Xiao-ma, Tan Jing, Chen Xu. (2013). A study on city efficiency based on the resources view: A case of 16 cities of Yangtze River Delta. China Population, Resources and
Environment, 23(1).

Wang Hongling, Li Daokui, \& Feng Junxin. (2006). FDI and independent research: Empirical research based on industry data. Economic Research Journal, 2, 44-56.

Xu Min, \& Jiang Yong. (2014). China's market-oriented process promotes the development of urbanization? - Evidence from spatial Durbin model. Finance \& Economics, 8, 109-119.

Xu Jian-wei, Xu Xin-yu, Chen Xing-peng et al. (2013). Urban Efficiency Evaluation Based on DEA Cross Model in Gansu Province. Journal of Natural Resources, 28(4).

Yuan Xiaoling, Zhang Baoshan, \& Zhang Xiaoni. (2008). Urban efficiency evolution features. Urban Development Studies, 6, 102-107.

Zeng Zhaofa, \& Zuo Jie. (2013). Chinese provincial urban agglomeration of space and the driving mechanism - Based on spatial panel data model. Chinese Journal of Management Science, S2, 580-586.

Zhang Haoran, \& Yi Baozhong. (2012). Infrastructure, spatial spillover and regional total factor productivity - Based on Chinese 266 urban spatial panel durbin model study. Economist, 2, 61-67.

China City Statistical Yearbook

China Statistical Yearbook

China Urban Construction Statistical Yearbook

\author{
Received on $7^{\text {th }}$ April 2016, \\ after revision, \\ accepted for publication on $22^{\text {nd }}$ August 2016. \\ Published online on $26^{\text {th }}$ August 2016.
}

Yuan Xiaoling is a Professor and a Doctoral Tutor at Xi'an Jiaotong University. She is devoted to doing research into urban economics and regional economics.

Chen Ali is a postgraduate at Xi'an Jiaotong University. He is devoted to doing research into urban economics. 


\title{
STUDIJA PROSTORNOG I POKRETAČKOG MEHANIZMA URBANE EFIKASNOSTI GRADOVA U KINI - NA OSNOVU MODELA PROSTORNIH PANEL PODATAKA
}

\author{
Yuan Xiaoling and Chen Ali \\ School of Economics and Finance of Xi'an Jiaotong University, Xi'an, Shaanxi, China
}

\begin{abstract}
U ovom radu su - primenom prostornog ekonometrijskog modela - analizirani faktori urbane efikasnosti 285 gradova na nivou prefektura, u Kini, u periodu 2003-2012. Dobijeni rezultati pokazuju da je razvoj urbane efikasnosti između gradova u pozitivnoj korelaciji sa prostorom. Zaključeno je da Industrijska struktura, Otvorenost i Infrastruktura mogu unaprediti razvoj urbane efikasnosti, a da Razmere urbane aglomeracije, Državna kontrola, Investiranje u osnovna sredstva i drugi faktori mogu u određenom stepenu usporiti razvoj urbane efikasnosti. Stoga je zaključeno da gradovi - u novom procesu urbanizacije - treba da ostvare međuregionalnu koordinaciju iz perspektive gradskih aglomeracija i razvoja metropola. Takođe, efikasnost grada zajedno sa naučnim i racionalnim tokom odnosnih faktora treba biti unapređena.
\end{abstract}

Ključne reči: urbana efikasnost, SBM model, prostorni ekonometrijski model, priliv faktora

JEL Classification: R12 